\title{
Tratamento do transtorno dismórfico corporal com venlafaxina: relato de caso
}

\section{Treatment of body dysmorphic disorder with venlafaxine: a case report}

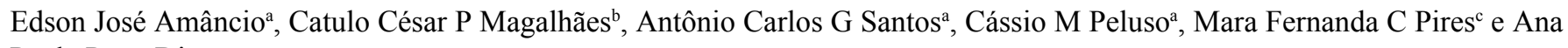
Paula Peña-Dias ${ }^{\mathrm{a}}$

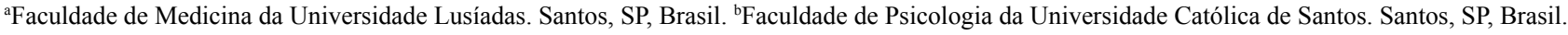
'Pontifícia Universidade Católica de São Paulo. São Paulo, SP, Brasil

Resumo O trabalho descreve um paciente com transtorno dismórfico corporal que respondeu preferencialmente com venlafaxina. Além disso, revisa a literatura sobre o assunto e discute similaridades e diferenças com o distúrbio obsessivo-compulsivo.

Descritores Dismorfofobia corporal. Transtorno obsessivo-compulsivo. Antidepressivos.

Abstract A body dysmorphic disorder (BDD) patient who responded preferentially to venlafaxine is described. A literature review was carried out, and the paper also discusses the similarities and differences between BDD and obsessive-compulsive disorder.

Keywords Body dysmorphic disorder. Obsessive-compulsive disorder. Antidepressive agents.

\section{Introdução}

O transtorno dismórfico corporal é definido como uma preocupação excessiva com um defeito imaginário na aparência física. É conhecido mais comumente como dismorfofobia. ${ }^{1}$ No DSM-IV, é classificado como um transtorno isolado e denominado transtorno dismórfico corporal (TDC).

Embora TDC tenha sido descrito na literatura ao longo de vários anos, é surpreendente o pouco conhecimento a respeito dessa condição.

TDC em geral produz morbidade significativa. Muitos pacientes evoluem com perdas ocupacionais e sociais importantes e muitos permanecem isolados dentro de casa durante anos. ${ }^{1}$

A proximidade entre TDC e transtorno obsessivo-compulsivo (TOC) tem sido referida em alguns trabalhos. ${ }^{1-5}$

Há dados na literatura sugerindo que o TDC é relativamente comum em pacientes com transtorno depressivo, ${ }^{5}$ fobia social, ${ }^{6} \mathrm{TOC}^{7-9}$ e naqueles que procuram tratamento dermatológico e cirurgia plástica. ${ }^{1,5,8}$

A maioria dos pacientes com TDC busca tratamento nãopsiquiátrico, como cirúrgico ou dermatológico, que, no caso dessa patologia, estão fadados ao insucesso. ${ }^{5}$ Dados oriundos de estudos abertos sugerem que os inibidores da recaptação da serotonina são geralmente e, talvez, preferencialmente, efeti- vos no tratamento do TDC. ${ }^{9,10}$ No presente trabalho, os autores descrevem uma paciente com TDC que apresentou remissão dos sintomas pelo tratamento com venlafaxina e discutem a possível associação dessa patologia com o TOC.

\section{Apresentação do caso}

C., 39 anos, sexo feminino, solteira, de nível universitário.

Refere que há dez anos apresentou, sem motivo aparente, vários episódios seqüenciais nos quais tinha tontura, opressão no peito, insônia, medo de ficar sozinha, insegurança para dirigir e sensação de que lhe faltava o ar. Nessa época, foi medicada com clomipramina obtendo melhora dos sintomas.

Havia cerca de dois meses, ao achar que a musculatura da face se tornara flácida, iniciou uma seqüência de exercícios físicos para reforçá-la. Colocava na boca um dispositivo metálico, como se fosse uma mola que distendia suas bochechas, e fazia diariamente uma série de exercícios durante mais ou menos 15 minutos. Concomitantemente, começou a se sentir insegura, não saía à rua desacompanhada, deixou de dirigir, permanecendo a maior parte do tempo trancada em seu quarto. Nessa mesma época, notou contrações faciais involuntárias, a tal ponto que, às vezes, apresentava dificuldade para falar. Passou a se olhar constantemente ao espelho com a nítida impressão de que suas faces esta-

Recebido em 12/9/2000. Revisado em 7/5/2001; 19/10/2001 e 27/3/2002. Aceito em 8/4/2002.

Fonte de financiamento e conflito de interesses inexistentes. 
vam caídas. Pergunta insistentemente aos familiares sobre sua própria aparência e sente-se inconformada com o fato de que seus familiares "se recusam a enxergar" as alterações que lhe ocorrem no corpo. Está firmemente convencida de que a musculatura da face está flácida e de que as bochechas desabaram. Toca constantemente o rosto, repetidas vezes durante a consulta, como se quisesse manter os músculos elevados. Refere também insônia e incapacidade de se relacionar com pessoas do sexo masculino. Queixa-se de que já teve algumas relações amorosas frustradas e de que "tudo o que começa não vai pra frente". Cursou engenharia química, mas não exerceu a profissão. Refere ter dificuldade nos relacionamentos pessoais; afastou-se do convívio social, apresenta falta de motivação e medo do futuro. Não há antecedentes mórbidos psiquiátricos entre os familiares. A paciente refere com insistência que não só a face está flácida e caída, mas também os seios e as nádegas.

Refere também ter-se submetido à psicoterapia há dez anos, durante três meses. A motivação para a procura desse tipo de tratamento foi timidez, insegurança e crises de pânico, além de dificuldades nos relacionamentos interpessoais. Não conseguia tomar nenhuma decisão relativa a seu futuro. Nega ter obtido qualquer benefício com a psicoterapia. Nega ter feito uso de qualquer droga ou medicamento à época em que os sintomas corporais apareceram. Ainda não se submeteu a nenhum tipo de tratamento medicamentoso para o problema atual, exceto tomar alprazolam $0,5 \mathrm{mg} /$ dia na tentativa de reduzir sua ansiedade e insônia.

O exame clínico mostra uma mulher jovem de boa aparência, bem vestida, comunicando-se normalmente, orientada têmporo-espacialmente e alopsiquicamente. $\mathrm{O}$ exame da face não mostra alterações na pele, o tônus muscular é normal, os movimentos faciais são normais e simétricos, a sensibilidade cutânea da face é normal, o reflexo córneo-palpebral está presente bilateralmente, não há evidência de atrofias ou outras alterações de qualquer natureza. Não há também nenhuma evidência de que tenha alterações nos seios ou nádegas. Mini Mental State Examination $(\mathrm{MM})=30$ pontos.

Foram realizados os seguintes exames laboratoriais: hemograma, glicemia, uréia e creatinina, T3, T4, TSH, EEG, $\mathrm{TC}$ de crânio, cujos resultados foram normais.

Optou-se por medicá-la inicialmente com $75 \mathrm{mg}$ de venlafaxina/dia.

No final da primeira semana de tratamento, a paciente referia nítida melhora dos sintomas corporais. Houve redução da ansiedade e melhora do sono. Havia reduzido o número de vezes em que se olhava ao espelho, porém admitia que o desânimo e a falta de motivação, bem como o isolamento, não haviam sofrido melhora significativa.

Foi decidido aumentar a dose de venlafaxina para $75 \mathrm{mg}$ duas vezes ao dia.

Nova avaliação foi realizada 30 dias depois, quando, então, a paciente estava assintomática. Dormia bem, não se sentia depressiva, havia melhorado o contato com os familiares, saía desacompanhada à rua, dirigia e não se olhava ao espelho de forma compulsiva. Foi sugerida a manutenção do esquema terapêutico, com revisões periódicas mensais. Seis meses depois do início do tratamento, a paciente permaneceu assintomática.

\section{Discussão}

Não há consenso entre os autores quanto à definição de TDC ou dismorfofobia. Ela foi definida pela primeira vez por Morselli ${ }^{11}$ em 1886, que a descreveu como "um sentimento subjetivo de feiúra ou defeito físico no qual os pacientes sentem que são observados por terceiros, embora sua aparência esteja dentro dos limites da normalidade". Esses sintomas são geralmente vistos como distúrbios da imagem corporal. Podem ser induzidos por estados orgânicos, por drogas e, notadamente, por graves patologias cerebrais. ${ }^{7} \mathrm{O}$ distúrbio da imagem corporal pode progredir para um delírio primário, uma idéia delirante ou uma idéia supervalorizada. ${ }^{7} \mathrm{Hay}^{6}$ sugeriu que o tema dismorfofóbico expressa idéias supervalorizadas. Desde então alguns autores têm qualificado a natureza da conviç̧ão desses pacientes. Quando a convicção é um simples e solitário delírio, e, portanto, a personalidade está intacta, presumivelmente o diagnóstico deve ser de uma psicose monossintomática. ${ }^{12}$

Alguns autores vêem o TDC como tendo origem em conflitos inconscientes. ${ }^{13}$ Virtualmente, qualquer parte do corpo pode ser objeto do TDC, mas há predomínio para alvos como pele (pequenas escaras, acne), orelha, nariz, cabeça e face. Com freqüência estão associadas idéias ou delírios de referência, bem como comportamentos ritualísticos e repetitivos, como olhar várias vezes ao espelho para checar o defeito imaginário, picar repetidas vezes a pele e questionar persistentemente os outros em busca de confirmação do defeito. ${ }^{5}$

Connolly \& Gipson ${ }^{8}$ e $\mathrm{Hay}^{6}$ encontraram taxas entre os gêneros semelhantes em pacientes do sexo masculino e do sexo feminino em suas amostras. A faixa etária predominante de aparecimento do TDC é na adolescência. ${ }^{5}$

A questão que parece indefinida até o momento é se o TDC deve ser considerado um distúrbio mínimo, uma entidade isolada ou um sintoma de uma doença subjacente. Esta última hipótese parece indiscutível do ponto de vista clínico. Em várias séries ${ }^{6,8,14}$ totalizando 266 pacientes com TDC, 111 pacientes não apresentaram nenhuma comorbidade com outras doenças psiquiátricas. Baseado nesses dados, Thomas ${ }^{7}$ sugeriu que o termo TDC deve ser empregado somente para pacientes sem qualquer outra doença psiquiátrica classificável e que TDC secundário ou sintomático deve ser usado quando alguma outra doença mental for responsável pelos sintomas.

No DSM-IV, ${ }^{2}$ o TDC é diagnosticável por três critérios necessariamente presentes: (1) preocupação com um defeito imaginário na aparência, ou, se na presença de uma ligeira anomalia física, o indivíduo apresentar-se excessivamente preocupado; (2) preocupação como causa de sofrimento clinicamente significativo ou prejuízo no funcionamento ocupacional ou em outras áreas importantes da vida do indivíduo; (3) preocupação sem possibilidade de ser explicada por qualquer outro transtorno mental, tal como anorexia nervosa, por exemplo.

Phillips et a ${ }^{15}$ analisaram 30 casos de TDC e assinalaram que geralmente um transtorno do humor, particularmente depressão maior, é o mais comumente associado a TDC, e que este geralmente coexiste com TOC e fobia social.

$\mathrm{Na}$ paciente do presente relato, todos os critérios diagnósticos descritos no DSM-IV ${ }^{2}$ para TDC foram preenchi- 
dos. Ela se olhava inúmeras vezes ao espelho em busca do defeito imaginário e perguntava insistentemente aos familiares, à procura de confirmação para suas constatações, sobre sua aparência; algumas vezes acordou durante a madrugada, ascendeu a luz e foi se olhar ao espelho. Durante o exame clínico realizado na primeira consulta, mostrou-se surpresa e, até certo ponto, indignada com a relutância dos examinadores em confirmar alterações em sua face, seios e nádegas. Quando perguntada sobre a intensidade de sua crença no transtorno corporal, reagia com incredulidade: "Não é possível que vocês não achem que minhas bochechas estejam caídas". E, pelo menos em uma ocasião, rebateu as negativas do examinador com a seguinte expressão: "Será que estou exagerando?", permitindo, portanto, a intromissão da dúvida em suas próprias afirmações.

Nenhum dos examinadores, no entanto, ficou convencido de que a intensidade da sua crença no defeito corporal atingisse o nível da idéia delirante. Quando suas perguntas eram negadas, ela assumia um semblante interrogativo, como se colocasse em dúvida sua própria crença no defeito corporal.

No entanto, diferentemente do que com freqüência ocorre em pacientes com TOC, a paciente em nenhum momento expressou pensamentos do tipo "eu sei que isto não está ocorrendo, mas não consigo deixar de pensar dessa maneira".

Embora haja evidências de comportamento compulsivo na paciente, especificamente relacionado a um defeito imaginário no próprio corpo, e, a despeito da proximidade entre TDC e TOC referida por vários autores, não se considera que esse comportamento, embora repetitivo e de certa forma ritualístico, deva ser enquadrado como TOC. A semelhança com essa condição clínica restringiu-se exclusivamente às repetidas miradas da paciente ao espelho e às perguntas alusivas a sua aparência.
$\mathrm{O}$ fato de que, nessa paciente, os sintomas relacionaram-se a face, seios e nádegas corrobora as observações de outros autores quanto à ocorrência de múltiplas localizações do TDC no mesmo indivíduo. ${ }^{16}$

Vários antidepressivos têm sido utilizados para o tratamento do TDC, como tricíclicos, clomipramina, fluoxetina, ${ }^{5}$ fluvoxamina ${ }^{16}$ e inibidores da MAO, ${ }^{5}$ e é sabido que esses pacientes respondem insatisfatoriamente com o uso de neurolépticos isolados. ${ }^{10}$ Hollander et al $^{4}$ relataram bons resultados com o uso de potentes bloqueadores de recaptação da serotonina (fluoxetina e clomipramina). Não há uniformidade nos resultados da psicoterapia para o tratamento do TDC. ${ }^{16}$ Entretanto, estudos sobre a ação dos inibidores de recaptação da serotonina têm mostrado resultados promissores, comparados a outros agentes farmacológicos, como neurolépticos e drogas anticonvulsivas. ${ }^{4}$

A paciente obteve melhora progressiva com doses crescentes de venlafaxina, iniciada com $75 \mathrm{mg} /$ dia até a dose final de $150 \mathrm{mg} /$ dia. Seis meses depois de iniciado o tratamento, ainda permanecia assintomática.

Aparentemente, a venlafaxina apresenta efeitos ansiolíticos importantes, o que tornou possível sua manutenção como monoterapia. O reajuste gradual da dose certamente contribuiu para impedir o aparecimento de efeitos colaterais, como náuseas, sonolência ou agitação, freqüentemente observados com neurolépticos, ansiolíticos e outros antidepressivos.

Em conclusão, pode-se dizer que o caso clínico em questão ilustra a ocorrência do TDC como condição clínica mínima, não necessariamente associado a outras enfermidades psiquiátricas como TOC ou esquizofrenia, e que a venlafaxina pode ser uma opção para o tratamento desse transtorno.

\section{Referências}

1. Philips KA, Mc Elroy SL. Insight, overvalued ideation, and delusional thinking in body dysmorphic disorder: Theoretical and treatment implications. J Nerv Ment Dis 1993;181:699-702.

2. American Psychiatric Association. Diagnostic and statistical manual of mental disorders. 4th ed. Washington (DC): American Psychiatric Association; 1994.

3. Insel TR, Akiskal HS. Obsessive-compulsive disorder with psychotic features: a phenomenologic analysis. Ann J Psychiatry 1986;143:1527-33.

4. Hollander E, Libowitz MR, Winchel R, Klumker A, Klein DF. Treatment of body dysmorphic disorder with serotonin reuptake blockers. Am J Psychiatry 1989;146:768-70.

5. Phillips KA, Kim JM, Hudson JL. Body image disturbance in body dysmorphic disorder and eating disorder. Obsessions or delusions? Psychiatr Clin North Am 1995;18:317-34.

6. Hay GG. Dysmorphophobia. Br J Psychiatry 1970;116:85-97.

7. Thomas CS. Dysmorphophobia; a question of definition. Br J Psychiatry 1984;144:513-6.

8. Connoly FH, Gipson M. Dysmorphophobia: a longterm study. Br J Psychiatry 1978;132:568-70.

9. Brady KT, Austin L, Lydiard RB. Body dysmorphic disorder: the relationship to obsessive-compulsive disorder. J Nerv Ment Dis 1990;178:538-40.

10. Hollander E, Cohen D, Simeon D. Fluvoxamine treatment of body dysmorphic disorder. J Clin Psychopharmacol 1994;14:75-7.

11. Morcelli E. Sulla dismorfofobia e sulla tafefobia. Bollet R Accad Genova 1886;6:100-19.

12. Munro A. Monosymptomatic hypochondriacal psychosis. Br J Hosp Med 1980;24:34-8.

13. Hill G, Silver AG. Psychodynamic and aesthetic motivations for plastic surgery. Psychosom Med 1950;12:347-57.

14. Edgerton MT, Jacobson WE, Meyer E. Surgical-psychiatric study of patients seeking plastic (cosmetic) surgery: ninety-eight consecutive patients with minimal deformity. Br J Plastic Surgery 1960;13:136-45.

15. Philips KA, Mc Elroy SL, Keck PE Jr, Pope HG Jr, Hudson JI. Body dysmorphic disorder: 30 cases of imagined ugliness. Am J Psychiatry 1993;150:302-8.

16. Philips KA, Mc Elroy SL. Obsessive-compulsive disorder in relation to body dysmorphic disorder. Am J Psychiatry 1992;149:184.

\section{Correspondência:}

Edson José Amâncio

Rua Nascimento, 27/71, Boqueirão

11040-170 Santos, SP, Brasil

Tel.: (0xx13) 3288-2829

E-mail: edson-amancio@uol.com.br 